\title{
Ordem e Progresso, de Deodoro a Temer: uma trajetória de sentidos
}

\author{
Ordem e Progresso, from Deodoro da Fonseca to Michel Temer: a pathway \\ through meaning
}

\section{Ordem e Progresso, de Deodoro da Fonseca a Michel Temer: un camino a través de los significados}

\section{André Campos Mesquita* (Dhttps://orcid.org/0000-0001-9896-9378}

\begin{abstract}
RESUMO: Este artigo tem como objetivo apresentar uma análise dos significados da expressão Ordem e Progresso em dois momentos: como lema da Bandeira Brasileira e como slogan do governo Michel Temer. O slogan foi inspirado no lema da Bandeira Brasileira, que, por sua vez, se inspirou nos trabalhos do filósofo francês do século XIX, Augusto Comte. Analisarei o texto do autor do lema e alguns textos dos filósofos positivistas brasileiros, que idealizaram a bandeira da República Federativa do Brasil no governo do presidente Deodoro da Fonseca. Também propomos pensar no discurso dos jornais brasileiros e em como eles reproduzem a ideologia das classes dominantes, para compreender de que maneira o lema da bandeira brasileira, ao ser recuperado em 2016, reitera o discurso da ideologia dominante. Analisarei esses textos como enunciados definidos por seus momentos históricos. Este artigo articula algumas concepções fundamentais dos estudos de enunciados (BENVENISTE, 1989; DUCROT,1987) com as teorias da análise de discurso de Bakhtin e Voloshinov (1988) e Pêcheux (1997).
\end{abstract}

PALAVRAS-CHAVE: Ordem e Progresso. Análise de discurso. Bandeira do Brasil.

ABSTRACT: This paper aims to present an analysis of the meanings of the expression Ordem e Progresso in two moments: as a motto of the Brazilian flag and as a slogan of the Michel Temer government. This slogan was inspired by the motto of the Brazilian National Flag, which in turn was inspired by the works of the $19^{\text {th }}$ century French philosopher Augusto Comte. We will analyze the text of the author of the motto, and some texts of Brazilian positivist philosophers who created the flag of the Federative Republic of Brazil under President Deodoro da Fonseca's administration. We also propose to think about the discourse of Brazilian newspapers, and how they reproduce the ideology of the ruling classes. We analyzed these texts as utterances defined by their historical moments, to understand how the motto of the Brazilian flag, when recovered in 2016, reiterates the discourse of the dominant ideology. This paper articulates some fundamental conceptions of utterance studies (BENVENISTE, 1989; DUCROT,1987) with Bakhtin and Voloshinov(1988) and Paychex's (1997) theories of discourse analysis.

KEYWORDS: Order and Progress. Discourse analysis. Brazilian Flag.

\footnotetext{
* Doutor em Linguística. Professor Adjunto na Universidade de Maringá. E-mail: andre.mesquita@usp.br
} 
RESUMEN: Este artículo tiene como objetivo presentar un análisis de los significados de la expresión Ordem e Progresso en dos momentos: como divisa de la bandera brasileña y como eslogan del gobierno de Michel Temer. El eslogan se inspiró en el lema de la Bandera Nacional de Brasil que, a su vez, se inspiró en las obras del filósofo francés del siglo XIX, Augusto Comte. Analizaremos el texto del autor del lema y algunos textos de los filósofos positivistas brasileños, que han diseñado la bandera de la República Federativa de Brasil bajo el gobierno del Presidente Deodoro da Fonseca. También proponemos pensar en el discurso de los periódicos brasileños y en cómo estos periódicos reproducen la ideología de las clases dominantes, para entender cómo el lema de la bandera brasileña, cuando se recuperó en 2016, reitera el discurso de la ideología dominante. Analizaremos todos estes textos como enunciados definidos por sus momentos históricos. Este artículo articula algunas concepciones fundamentales de los estudios de enunciación (BENVENISTE, 1989; DUCROT, 1987) con la teoría del análisis del discurso de Bakhtin yVoloshinov (1988) y Pêcheux (1997).

PALABRAS CLAVE: Orden y progreso. Análisis del discurso. Bandera Nacional de Brasil.

\section{Introdução}

O objetivo deste trabalho é analisar a expressão Ordem e Progresso empregada como divisa na Bandeira do Brasil em 1889 e retomada como slogan do governo Michel Temer em 2016. Irei empregar a palavra lema quando estiver me referindo à expressão na obra de seu criador e de seus seguidores (Miguel Lemos, Raymundo Teixeira Mendes, Juan Enrique Lagarrigue), divisa quando me referir à bandeira e slogan quando estiver me referindo ao logo do Governo Michel Temer; a palavra expressão será relacionada a Ordem e Progresso como um recurso metalinguístico para designar todos os três acontecimentos linguísticos analisados neste artigo. Tomarei o lema, a divisa e o slogan como enunciados distintos, cada um como um acontecimento enunciativo único marcado na história.

Na primeira parte deste artigo, as análises vão procurar compreender os sentidos da expressão Ordem e Progresso por meio de uma leitura da obra do filósofo positivista francês Augusto Comte ${ }^{1}$; em seguida, buscarei compreender a divisa da bandeira do Brasil inserida no contexto histórico e social em que ela foi confeccionada, incluindo nas análises uma leitura de excertos das obras de positivistas latino-americanos do período,

\footnotetext{
${ }^{1}$ A filosofia de Comte não é fundamentação teórica deste artigo, ela é objeto de análise. Eu não tenho interesse em fazer uma análise positivista de uma frase, mas sim entender de que modo as regras de formação do discurso que legitimavam Comte dizer o que disse, no século XIX, reverberam ainda hoje e estão em conformidade com um conjunto de discursos aparentemente dispersos. A leitura da filosofia de Comte tem como objetivo compreender a que ideologia ela se reporta.
} 
para, por fim, discorrer sobre a enunciação relativa ao slogan do governo Temer. Nessa última análise, lançarei mão de uma reflexão sobre as regras de construção discursiva daquele momento, fazendo uso de alguns excertos de jornais e livros que se referem aos governos anteriores ao de Michel Temer, respectivamente Luiz Inácio Lula da Silva e Dilma Rousseff. A ideia é compreender com quais discursos o slogan do governo Temer estabelece relação. A hipótese que defendo e que pretendo demonstrar por meio dessa relação é de que a escolha da expressão Ordem e Progresso como slogan do governo Temer não ocorre em um vácuo, mas se reporta ao discurso de uma parcela específica da elite brasileira, que colaborou direta ou indiretamente para a derrubada do governo da presidente Dilma Rousseff. Isso nos servirá de base para entender como a divisa da bandeira faz parte de uma construção discursiva elitista e excludente.

A divisa Ordem e Progresso, presente na bandeira da República Federativa do Brasil, tem sua origem em um lema criado pelo filósofo positivista francês Augusto Comte. Gouhier (1965) afirma que Comte, assim como outros filósofos, criava termos - como é o caso de altruísmo e sociologia (GRANGE, 2002) - e lemas como uma espécie de bordão para difundir sua Religião da Humanidade (COMTE, 1852). Entre esses lemas podemos destacar Viver às claras (vivre au grand jour), Viver para outrem (vivre pour autrui) e 0 Amor por princípio, e a Ordem por base; O Progresso por fim (L'Amour pour principe, I'Ordre pour base, et le Progrès pour but).

Antes de progredir em minha análise, considero de extrema importância de deixar claro um aspecto relativo a uma alegada origem do lema Ordem e progresso. Há uma informação equiovocada disseminada em diversos veículos e publicações como o projeto de Lei 2179/2003 de autoria do deputado Chico Alencar (CÂMARA DOS DEPUTADOS, 2003), o livro 1889: Como um imperador cansado, um marechal vaidoso e um professor injustiçado contribuíram para o fim da Monarquia e a Proclamação da República no Brasil de autoria do historiador Laurentino Gomes (GOMES, 2013), e até mesmo no verbete Ordem e progresso que aparece na Wikepedia². Segundo essas fontes o lema Ordem e progresso teria se originado do lema religioso de Comte: O Amor por princípio, e a Ordem

\footnotetext{
2 Cito a Wikipedia não como fonte de pesquisa ou embasamento teórico, mas apenas para demonstrar o quanto essa informação aparece disseminada em diversos locais. Até o dia 28 de março ainda constava a informação equivocada na Wikipedia de que o lema político Ordem e progresso, tinha origem no lema religioso.
} 
por base; O Progresso por fim. Nenhuma das fontes anteriormente mencionadas (CÂMARA DOS DEPUTADOS, 2003; GOMES, 2013) apresenta evidências que permitam fazer tal afirmação.

O lema político Ordem e Progresso aparece pela primeira vez em 1844 na obra Discours sur l'esprit positif. Enquanto o bordão religioso, O Amor por princípio, e a Ordem por base; O Progresso por fim, só irá aparecer em seus escritos, sete anos mais tarde, em 1851 em Système de politique positive. Não há na obra de Comte afirmações que deem sustentação à tese de que o lema político tenha se originado do bordão religioso; o mais provávelé que tenha acontecido o contrário, uma vez que o lema político é anterior ao bordão religioso.

Por essa razão, neste artigo tratarei apenas do lema Ordem e Progresso, não levando em conta a afirmação sem fundamento de que ele tenha se originado do bordão O Amor por princípio, e a Ordem por base; O Progresso por fim.

Comte (1830) acreditava que, da mesma forma que a biologia distingue o ponto de vista dinâmico (relativo à estrutura do organismo) do ponto de vista fisiológico (relativo à vida), a sociologia também deveria separar os estudos das condições de existência de uma sociedade (estático) e das leis de seu movimento (dinâmico). É nessa visão que ele fundamentou o lema Ordem e Progresso.

Comte entendia que havia uma distinção entre as leis da estática social (ordem) das leis da dinâmica social (progresso). O princípio básico da estática, para ele, era o consenso de que as classes sociais (proletário, industrial, sacerdote e mulher) deveriam ser resignar à sua condição social e passariam a interagir trabalhando pelo progresso.

O progresso, no entendimento de Comte (1848), iria promover a melhoria das condições de vida, sem que necessariamente houvesse mobilidade entre as classes sociais. Progresso, em sua proposta de filosofia, estaria diretamente ligado e dependeria do estabelecimento da ordem. Dessa perspetiva, depreende-se que Comte pensava que cada classe social deveria permanecer em seu lugar. Nesse sentido, sua visão era rigorosamente contrária à dos socialistas. Conforme Lacerda (2004), para Comte, cada classe social teria seu próprio tipo de poder, conforme veremos adiante.

Comte (1848) apresenta Ordem e Progresso com o objetivo de que ele se tornasse uma divisa para as bandeiras ocidentais. Em sua ideia, esse lema deveria ser uma refu- 
tação ao lema da revolução francesa: Liberdade, Igualdade e Fraternidade. Comte acreditava que as garantias individuais estariam ligadas à universalidade das obrigações entre cidadãos.. Em sua ideia, deveria haver a substituição da moral passiva pela moral ativa e altruísta na qual convém a cada um fazer o seu dever e a sua parte. Ser altruísta significava viver para outrem de acordo com Comte (1848), uma tendência que, para ele, seria natural de todos os homens e que se consolidaria dentro da família e deveria ser ampliada a toda sociedade. O altruísmo é, para o positivista, uma das peças fundamentais na organização do seu sistema político e religioso.

Por essa razão, para Comte (1848), a fraternidade estaria relacionada a essas obrigações, garantindo o que se poderia esperar da igualdade. Para ele, liberdade e igualdade seriam ideias contraditórias e opostas, já que a noção de liberdade pode nos conduzir ao individualismo e às diferenças.

No lema Ordem e Progresso, Comte (1848) enxergava uma ideia de ordem vinculada à ideia do progresso. Nesse caso, segundo o positivista, em vez de se anularem em um compromisso vago como Liberdade e Igualdade; Ordem e Progresso se multiplicariam. Como se vê, Comte não era um filósofo que considerava a democracia um sistema político viável. Sua visão de estado não dava direito de atuação política para as mulheres nem para o operariado. O poder político, no pensamento do positivista, deveria se concentrar nas mãos dos empresários da indústria.

É preciso entender ainda que Comte se opunha à ideia tradicional de que ordem é algo eterno e imutável, e que o progresso é uma ruptura com o passado. Ele afirma: "O progresso é o desenvolvimento da ordem"33 (COMTE, 1851, p. 216). Desse modo, para ele, o progresso dinâmico e a ordem estática deviam ser complementares e estariam intimamente ligados; um era, em seu pensamento, consequência direta do outro.

Os dois termos seriam então inseparáveis, segundo o entendimento de Comte: "A ordem torna-se condição permanente do progresso, enquanto o progresso é a finalidade da ordem ${ }^{4}$ (COMTE, 1851, p. 105); ou seja: um não poderia existir sem o outro.

Ordem e Progresso aparecem encadeados pela primeira vez em uma obra de Comte de 1848, em Discours sur l'ensemble du positivisme:

\footnotetext{
${ }^{3}$ le progrès est le développement de l'ordre.

${ }^{4}$ L'ordre devient alors la condition permanente du progrès, tandis que le progrès constitue le but de l'ordre. Texto original em francês, tradução minha.
} 
[...] por outro lado, à medida que o curso natural dos eventos caracteriza a grande crise moderna, a reorganização política se apresenta cada vez mais necessariamente impossível sem a reconstrução prévia das opiniões e da moral. Uma sistematização verdadeira de todos os pensamentos humanos constitui então nossa primeira necessidade social, igualmente relativa à ordem e ao progresso (COMTE, 1848, p. 53) ${ }^{5}$.

O enunciador Comte apresenta no parágrafo acima duas sentenças em que encontramos um argumento e uma conclusão. Ele assume um ponto de vista que quanto menos "reconstrução prévia das opiniões e da moral", menos se torna possível a "reorganização política". Assim, podemos concluir que da perspectiva de Comte, as "opiniões e a moral" estão diretamente relacionadas à "reorganização política", pois conduzem à conclusão da frase seguinte: "Uma sistematização verdadeira de todos os pensamentos humanos constitui então nossa primeira necessidade social, igualmente relativa à ordem e ao progresso" (COMTE, 1848, p. 53).

Em sua Lei dos Três Estados (COMTE, 1854), a sociedade teológica e militar tende a desaparecer na passagem dos Estados Teológico e Metafísico para o Estado Positivista. Comte afirma que, em seu lugar, surgiria uma sociedade científica e industrial; os sacerdotes seriam substituídos por cientistas; e os militares dariam lugar aos industriais (diretores de fábricas e banqueiros).

Os cientistas viriam a compor uma classe social que nos tempos passados seria a dos teólogos e sacerdotes, essa classe seria - para Comte - responsável pelo Poder Espiritual. A sua função social seria a de determinar o comportamento dos demais cidadãos por meio do pensamento "científico" e não mais com base nos dogmas religiosos, como o sacerdote. Conforme Lacerda (2004), o Poder Espiritual não dá ordens, não manda; ele apenas apresenta doutrinas gerais que orientam a sociedade.

Além do Poder Espiritual, teríamos o Poder Temporal formado por duas outras classes sociais: o proletariado e a mulher. Esses, por sua vez, não opinam, eles apenas atuam para o desenvolvimento material da sociedade. Em linhas gerais, é isto que, para Comte, constitui a ordem social. A ordem que será a base do progresso. Lacerda (2004)

\footnotetext{
${ }^{5}$ [...] d'une autre part, à mesure que le cours naturel des événements caractérise la grande crise moderne, la réorganisation politique se présente de plus en plus comme nécessairement impossible sans la reconstruction préalable des opinions et des mœurs. Une systématisation réelle de toutes les pensées humaines constitue donc notre premier besoin social, également relatif à l'ordre et au progrès (COMTE, 1848, p. 53 (texto original em francês, tradução minha).
} 
afirma que Comte pensava que

\begin{abstract}
"o poder material tem eficácia prática, isto é: sua eficácia se daria sobre as coisas, sobre a realidade material, sobre o mundo, em outras palavras, por uma via direta; o poder espiritual age modificando a conduta do poder temporal, isto é, atua sobre os indivíduos, aconselhando, ensinando, sugerindo" (LACERDA, 2004, p. 71).
\end{abstract}

Nesse ponto, para Comte, o proletariado não deveria se ocupar das decisões (trabalho do poder espiritual) nem da condução política, que estariam a cargo do banqueiro e do diretor de fábrica.

Segundo Gouhier (1965), o positivista viu de sua própria janela o enfrentamento entre o operariado parisiense contra as tropas do general Cavaignac. Para Comte, era evidente que o proletariado, essa nova classe, não havia encontrado ainda o seu lugar dentro da sociedade. O proletário formava, segundo o positivista, apenas uma massa social e sequer podia ser tomado como uma classe verdadeira. Entretanto, essa massa era a base de sustentação das outras classes sociais: industrial, sacerdote e mulher. Conforme Bakhtin,

[...] por mais monológico que seja um enunciado (uma obra científica ou filosófica, por exemplo), por mais que se concentre no seu objeto, ele não pode deixar de ser também, em certo grau, uma resposta ao que já foi dito sobre o mesmo objeto, sobre o mesmo problema, ainda que esse caráter de resposta não receba uma expressão externa bem perceptível. A resposta transparecerá nas tonalidades do sentido, nos mais ínfimos matizes da composição (BAKHTIN, 1992, p. 317).

Com a elaboração do lema Ordem e Progresso, Comte atacava diretamente os movimentos da classe operária no século XIX. De acordo com Benoit (2002, p. 10), ele achava que, na Revolução de 1848, a classe operária não queria apenas comida e trabaIho. Estava claro para ele que as disputas sangrentas nas ruas de Paris simbolizavam um enfrentamento contra a burguesia pelo poder político. Ele não via com bons olhos que o poder político ficasse na mão do proletariado industrial. Para Comte, era preciso fazer com que o operariado se mantivesse em seu lugar, disciplinado e subordinado à ordem já estabelecida.

É justamente nesse ponto que o pensamento de Comte vai ao encontro tanto do ideal das elites que dominavam politicamente o Brasil na passagem da monarquia para a 
república, quanto dos atores que depuseram a presidente Rousseff.

\section{O governo Deodoro da Fonseca}

A atual bandeira da República Federativa do Brasil é uma reformulação pintada por Décio Villares do desenho feito pelo artista francês Jean Baptiste Debret para a bandeira do Império brasileiro. Com a instauração da República, em 1889, e o início do Governo de Deodoro da Fonseca, algumas versões para o estandarte foram apresentadas; a opção escolhida foi concebida pelos diretores do Apostolado Positivista do Brasil, Raimundo Teixeira Mendes e Miguel Lemos, e por Manuel Pereira Reis, catedrático de astronomia da Escola Politécnica do Rio de Janeiro. Nessa bandeira basicamente se retirou o brasão imperial, substituindo-o por um círculo, em que está estampada uma representação do céu em 15 de novembro de 1889, cortado por uma faixa branca em que se lê a divisa Ordem e Progresso.

A bandeira do Brasil foi projetada por dois positivistas: Raimundo Teixeira Mendes e Miguel Lemos, com desenho de Décio Vilares, na ocasião da Proclamação da República. Por sugestão de Benjamim Constant, essa divisa foi colocada no lugar do brasão imperial.

O positivista chileno Juan Enrique Lagarrigue (1889) comenta com entusiasmo a presença do lema político da Religião da Humanidade na Bandeira Brasileira.

A melhor prova do que digo está na circunstância de o Governo Republicano ter feito na nova bandeira nacional o lema político da Religião da Humanidade: Ordem e Progresso, e isso por conselho expresso dos apóstolos altruístas do Brasil ${ }^{6}$ (LAGARRIGUE, 1889, p. 7).

No mesmo artigo, Lagarrigue afirma que o Brasil deixava de ser o país mais atrasado do Ocidente - monárquico e escravocrata - para se tornar um dos mais evoluídos. O mesmo entusiasmo pode ser visto no artigo escrito pelo positivista Teixeira Mendes, um dos autores da bandeira, no Diário Oficial em 24 de novembro de 1889:

O povo brazileiro, como todos os póvos ocidentais, acha-se vivamente solicitado por duas necessidades ambas imperiózas, que se rezúmem nas palavras - Ordem e Progrésso. Todos sêntem, por um lado, que é imprecindivel manter as bazes da sociedade; mas todos percébem tambem que

\footnotetext{
${ }^{6}$ El mejor comprobante de lo que digo se encuentra en la circunstancia de que el Gobierno Republicano haya hecho en la nueva bandera nacional el lema político de la Religión da Humanidad: Orden y progreso, y eso por consejo expreso de los apóstolos altruistas del Brasil.
} 
as instituições humanas são sucetíveis de aperfeiçoamentos. Ora, acontecendo que o tipo da Ordem só foi até hoje fornecido pelo regimem teológico e guerreiro passado, e que o Progrésso tem ezigido a eliminação, por vezes violenta, de cértas instituições, o espírito público foi levado empiricamente a supôr que as duas necessidades érão irreconciliáveis (MENDES, 1958$, p. 8$)^{7}$.

Mendes defende categoricamente as manutenções das "bases da sociedade", o que está em consonância com o espírito da República e do governo de Deodoro da Fonseca que põe fim à monarquia brasileira. Não houve nenhuma modificação na estrutura social vigente, não houve confisco de terras ou propriedades privadas. A elite que estava no poder antes da República continuava no poder após a derrubada da Monarquia. Essa seria a tal ordem que sempre seria mantida no Brasil.

Mendes (1958) apresenta um ataque ao regime teológico e militar ${ }^{8}$ em que as duas ideias apareceriam como incompatíveis; quando o progresso traria uma eliminação violenta das instituições, para em seguida retomar Comte:

No entanto, a Dinâmica social, fundada por Augusto Comte, para completar e dezenvolver a Estática social fundada por Aristóteles, demonstra que as duas necessidades de Ordem e Progrésso, longe de serem irreconciliáveis, por toda a parte se harmonízão. E ainda mais, o mesmo egrégio Pensador demonstrou que essa harmonia se dá na política e na moral em consequência da preponderância do amor (MENDES, 1958, p.8).

Mendes afirma que Comte não vê a ordem como imutável e eterna nem o progresso como uma ruptura com o passado; há em seu discurso uma conciliação entre tradições políticas e morais e o desenvolvimento. Essa conciliação é o que dará sustentação à noção de Estática social. A concepção aristotélica pressupõe que cada indivíduo, ao desempenhar o seu papel, colabora com todo. Comte expande essa ideia para a separação dos ofícios e a convergência dos esforços em prol da sociedade. Assim, ele passa a observar as estruturas sociais sobre as quais a sociedade de seu tempo estava estabelecida. Para Comte, essas estruturas são a estática social, ou seja: cada classe social

\footnotetext{
7 A citação está na ortografia empregada por Mendes em seu artigo e como foi reproduzido na obra de 1958 (MENDES, 1958). Na ocasião da publicação do original (1889), não havia ainda uma grafia padrão para o português no Brasil. Optei por não inserir "sic" depois de cada uma das palavras para não prejudicar a leitura.

8 Mendes não faz uso do termo militar (militaire) empregado por Comte, preferindo a palavra guerreiro, talvez porque o golpe que instituiu a República brasileira em 1889 tenha partido de uma elite militar.
} 
deveria permanecer onde estava e o poder político deveria, segundo o positivista, pertencer ao empresário e ao financista. 0 discurso de que a política estaria em melhores mãos quando o governante atuasse como um "gestor" está em perfeita consonância com essas ideias.

\section{O governo Temer}

Uma vez que assumimos que o funcionamento da linguagem não é transparente, que os sentidos são afetados por um passado de enunciações e pelo lugar de um sujeito constituído nas e pelas relações sociais historicamente determinadas, propõe-se indagar as seguintes questões: a) Por que razão o governo interino recorreu especificamente a esse lema; b) a que dizeres e ideologia esse lema reporta quando retomado especificamente naquele momento histórico? Diante dessa perspectiva, me proponho a analisar o funcionamento semântico-enunciativo do slogan enunciado pelo governo Temer.

Irei considerar que a expressão Ordem e Progresso retomada pelo governo Temer é outra enunciação, que, contudo, é enunciada relativamente à divisa da bandeira. Essa outra enunciação carrega também outros sentidos, além de reiterar sentidos historicamente determinados em um passado de enunciações.

A reflexão sobre o sentido que tomarei neste artigo irá considerar que as duas enunciações são acontecimentos enunciativos. Em vista disso, é preciso deixar claro a que teoria da enunciação esta análise está relacionada. A definição considerada fundadora do campo de estudos da enunciação é de Benveniste (1989). Dentro dessa perspectiva, a enunciação é a apropriação da língua por um indivíduo que faz uso dela para dizer o que quer dizer. No instante em que ele enuncia, ele é locutor e instaura diante de si um alocutário.

Esse conceito de enunciação - como sendo uma atividade do locutor ao produzir um enunciado - pode nos levar a entender que o sujeito da enunciação é uno e único; que é senhor dos seus dizeres e - de modo onipotente - apropria-se da língua para dizer o que quer dizer. Entretanto, tal qual Ducrot $(1987$, p. 69) não irei assumir que a enunciação é o "ato de alguém que produz um enunciado". Não me interessa aqui a ideia de um sujeito autor, mas da enunciação como sendo um evento ou acontecimento histórico do aparecimento do enunciado.

Assumo ainda a propriedade dialógica da linguagem de Bakhtin e Voloshinov 
(1988, p. 88) e considero (conforme Bakhtin/ Voloshinov) que não há como evitar a natureza dialógica mútua do discurso, ou seja, da presença de um discurso anterior, de algo que já estava dito. Isso me permite tomar e entender a palavra sempre de um outro dito anterior. Um enunciador, ao produzir o seu discurso, é afetado inevitavelmente pelo discurso do outro, que é anterior ao seu. Assim, entendo que a expressão Ordem e Progresso retomada no governo Temer é de certo modo afetada pelo passado de enunciações que vão adicionando sentidos ao lema e à divisa da bandeira.

Isso me permite analisar o slogan proposto para o Governo Temer sem a necessidade de inferir se os responsáveis pela elaboração de tal slogan tinham ou não noção do que propunha Comte, ou do que pensavam os positivistas brasileiros responsáveis pela escolha do lema da bandeira. Conforme Pêcheux (1997, p. 160), palavras, expressões e proposições não existem "em si mesmo[as]", elas são determinadas pelas posições ideológicas que estão em jogo no processo sócio-histórico no qual são produzidas ou reproduzidas. Por essa razão, não é necessário que os responsáveis pelo slogan do governo Temer conheçam Comte ou tenham lido as suas obras para que se possa conectar o slogan à ideologia materializada pela enunciação do lema, pois uma vez que a linguagem é afetada pela história, o lema de Comte, a divisa da Bandeira e o slogan do governo Temer também o são. Conforme Pêcheux (1997) a linguagem não é transparente, e por essa razão se entende que os sentidos têm sua materialidade e são constituídos em processos em que tanto a língua quanto a história ou a ideologia concorrem de modo conjunto.

Essa concepção discursiva de Pêcheux permite explicar o modo como cada enunciado - seja o slogan do governo ou a divisa da bandeira - articula sentidos entre si. As posições sustentadas refletem de modo consciente ou não as suas posições ideológicas.

O slogan "Governo Federal: Ordem e Progresso" foi apresentado pelo governo interino após a aprovação do impeachment da presidente Dilma Rousseff. Em 12 de maio de 2016, a assessoria de Michel Temer, ainda interinamente na presidência na ocasião, anunciou que o slogan do novo governo seria: "Governo Federal: Ordem e Progresso". De acordo com o responsável pelo marketing do governo interino, a escolha do lema buscava [...] "recuperar o País da desorganização política, econômica e social e retomar o crescimento econômico" (GOVERNO..., 2016).

O termo ordem, presente no slogan, é colocado enunciativamente em oposição a 
desorganização; e o progresso é enunciado em posição de sinonímia a crescimento econômico a ser retomado.

Uma vez que temos esse termo tomado com um antônimo enunciativo de desorganização, temos de tentar entender o que está sendo referido como desorganização. Para Comte, conforme vimos, ordem se opõe semanticamente a revolução. Mais do que ter vivido a Revolução Francesa, Comte presenciou as revoltas em Paris em 1842 e 1848. Para ele, todas essas revoltas representavam uma desordem que afastaria a sociedade do progresso, pois no cerne dessas revoltas estava a busca do operariado pelo poder político.

Ao retomar a divisa da bandeira Ordem e Progresso, o governo Temer coloca a palavra ordem como uma maneira de se opor à eventual crise política e econômica que teria ocorrido no governo da presidente Rousseff.

E aqui está um ponto central desta análise: as circunstâncias em que a divisa Ordem e Progresso é retomada, tornando-se slogan do governo Temer. Adotar uma concepção dialógica da linguagem pressupõe aceitar que uma construção discursiva pode ser constituída por enunciados que à primeira vista não estão conectados e não parecem estar ligados por nenhum princípio de unidade. $\mathrm{O}$ analista do discurso, todavia, tem como tarefa olhar para esses enunciados aparentemente dispersos e entender com quais discursos eles dialogam.

A retomada da divisa da bandeira do Brasil para compor o slogan do governo Temer dialoga tanto com os discursos contemporâneos à criação do lema, como também com o conjunto de discursos que foram ao longo dos anos se somando a esses discursos. Desse modo, cabe reconhecer e identificar também nos discursos contemporâneos à criação do slogan discursos que deem sustentação à retomada da divisa da bandeira.

A expressão Ordem e Progresso foi enunciada em um tempo e local determinados historicamente, e tem um valor semântico ainda hoje; não apenas aquele que tinha no momento da sua primeira enunciação, mas uma série de sentidos que vão se somando na medida em que vamos estabelecendo relações dialógicas com esse e outros símbolos nacionais.

A análise de um lema concebido no Século XIX não impõe apenas uma volta ao passado, mas uma compreensão das condições de produção do discurso daquele tempo e de como essas condições de produção não ficam simplesmente no passado, mas vão 
se conformando à produção de novos discursos que ressurgem à medida que vão sendo estabelecidos diálogos com elas. A retomada da divisa faz sentido na medida em que entendemos que discursos como o de Comte continuam a ecoar de algum modo na atualidade. Deve-se destacar que mesmo Comte não era imune às influências externas em seus enunciados porque também eles eram afetados por um passado de enunciações.

É possível encontrar os ecos desse discurso nas declarações feitas por empresários, livros e matérias de jornal que apresentam enunciados aparentemente dispersos, mas que estão conectados por um conjunto de regras discursivas que permitem e legitimam que eles sejam enunciados. Todos os enunciados produzidos no interior desse conjunto de regras buscam se legitimar entre si e se perpetuarem, além de determinarem as regras de formação do discurso.

Os artigos analisados a seguir foram veiculados em sites e jornais durante o processo de impeachment da presidente Rousseff, ou fazem referências a esse período. Foram selecionados artigos que associavam ao governo da presidente expressões que poderiam estabelecer relação de antonímia com a expressão ordem, como desordem ou desgoverno. Proponho em primeiro lugar a análise de um artigo publicado no site da Rádio Jovem Pan em 2015, "O desgoverno de Dilma produziu distorções em relação ao Orçamento" (O DESGOVERNO..., 2015); e o artigo publicado na revista Veja de autoria de Moura Brasil: "Veja o panorama do desgoverno Dilma no fim de 2015" (MOURA BRASIL, 2017).

Nesses veículos de mídia, é propagado o discurso presente na ideologia dominante. Em A Ideologia Alemã, Marx e Engels (2007) afirmam que a classe dominante detém os meios de produção material e dispõe também dos meios de produção espiritual. Desse modo, é possível inferir que a classe dominante produz e dissemina ideias que atendem aos seus interesses, fazendo com que elas não pareçam ideias relacionadas a um segmento da sociedade, mas a um senso comum neutro e compartilhado por todos. Isso serve tanto para justificar ações violetas do Estado quanto textos regulatórios ou leis. Marx e Engels (2007) completam que a classe dominante controla tanto a produção de ideias quanto a regulamentação e distribuição das ideias de seu tempo.

Essa alegada desordem serviu como justificativa para o impeachment da presidente Rousseff, embora ele tenha ocorrido em decorrência de um alegado crime de responsabilidade fiscal e está em total consonância com o discurso das elites brasileiras, 
conforme pode ser lido na declaração do presidente da Fiesp, Paulo Skaf, dada à Agência Brasil em 17 de março de 2016: "[...] estou dizendo que o que acontece no Brasil hoje, onde nós chegamos em relação a essa desordem completa, a esse descontrole completo que não aconteceria em outros países" (BOCCHINI, 2016).

Skaf, um legítimo representante da elite empresarial paulista (ELITES..., 2011), ao ser questionado sobre quais teriam sido os crimes cometidos pela presidente Rousseff que motivaram o pedido de impeachment feito pela Fiesp, disse apenas que era pelo "conjunto dos fatos" (BOCCHINI, 2016). O discurso de Skaf é a materialidade da ideologia da classe dominante da qual ele faz parte. Para ele, é legítimo que uma entidade que representa 133 sindicatos patronais e cerca de 130 mil empresas privadas no estado de São Paulo (FIESP..., 2009; VENCESLAU; ROCHA, 2015) entre com um pedido de impedimento contra uma presidente de um partido trabalhista eleita democraticamente com base em um incerto "conjunto dos fatos" dentre os quais ele relaciona "falta de controle" e "desordem".

O discurso de Skaf revela a perpetuação da ideologia presente nos discursos dos positivistas de que o operariado deveria se manter fora do poder político, disciplinado e subordinado à ordem já estabelecida, em prefeita consonância com o lema Ordem e Progresso.

Por isso, é sintomático que o governo Temer tenha retomado o lema da bandeira, imediatamente após um partido de trabalhadores ter saído do governo. Para o discurso dominante, o trabalhador ou o cidadão oriundo de classes sociais menos abastadas apesar de a presidente Rousseff ser oriunda da classe média - não é capaz de conduzir o país rumo ao progresso.

As palavras proferidas de Skaf não são apenas uma expressão daquilo que ele próprio pensa sobre o governo da presidente Rousseff. As declarações de Skaf são enunciados que nos revelam algo além da opinião de um representante de uma classe de industriais. Essas declarações nos ajudam a compreender de que maneira a ideologia presente em seu discurso se faz verdade. Os enunciados de Skaf estão em consonância com as regras de produção de um discurso que materializa uma determinada ideologia; nesse caso, a ideologia da classe dominante. Suas falas são determinadas pelas posições ideológicas que se colocam em disputa no processo sócio-histórico. O discurso de Skaf articula sentidos com outros discursos, como, por exemplo, o artigo "Quero derrubar 
Lula" do colunista Mainardi da Revista Veja, edição 1916, em 9 de julho de 2005:

Todo mundo sabe que a melhor receita para o país é uma ampla reforma política. Lula é o maior obstáculo para que ela aconteça. Se ele for derrubado, tem reforma. Se não for, não tem. Lula, como sempre, é um fator de imobilismo e atraso. Seus partidários chantageiam o eleitorado com a ameaça de que sua queda trará a 'colombianização' ou a 'venezuelização' da sociedade. Mentira. Não há o que temer. Pior do que está não pode ficar (MAINARDI, 2007, p. 24).

Como se pode ver, essa mesma construção discursiva era comum também durante o governo anterior do presidente Lula: a necessidade de se depor um político eleito em nome do progresso, ou "contra o imobilismo e atraso".

$O$ artigo se inicia com um marcador universal de apelo a um senso comum: "Todo mundo sabe". Apesar de o discurso materializar a ideologia da classe dominante, esse recurso busca apagar os discursos contrários e negar-se a si o status de ideologia defendida por uma parcela da população. O presidente Lula é visto como "obstáculo" a ser "derrubado" e "fator de imobilismo e atraso".

Uma vez que Comte considera a ordem um elemento de manutenção da estrutura social - em que o proletário não participa das decisões políticas - e o estabelecimento da ordem uma condição inexorável para o progresso, a ideia de um presidente representante da política sindical e da classe operária representaria para o filósofo um obstáculo para o progresso.

O presidente Lula é tomado pelo colunista Mainardi como uma pessoa incapacitada para o cargo que ocupa. Ele nomeou o livro em que reuniu seus ataques ao presidente "Lula é minha anta", uma alusão a uma alegada incapacidade intelectual do presidente.

Em um país de grandes desigualdades sociais como o Brasil, em que a educação superior tem um alcance limitado, beneficiando na grande maioria das vezes apenas as classes sociais mais abastadas - a exigência, ainda que meramente discursiva, de um curso superior para o mandatário maior do país, faz parte de um discurso de exclusão da população mais pobre do debate político. Essa ideia se desdobra para a exclusão da classe trabalhadora da política como um todo. Especialmente do comando das decisões políticas. 
Comte era contrário à ideia de ter o trabalhador como partícipe nas decisões políticas; essa ideia era contrária à sua ideia de ordem. As decisões e a condução política deveriam vir de uma elite empresarial, assim como a produção intelectual e moral deveria ser uma produção exclusiva do cientista. Ao operariado caberia a função - dentro da sociedade positivista -de obedecer e trabalhar para o progresso. Essa é justamente a ideia expressa em Ordem e Progresso proposta por Comte.

\section{Conclusão}

Para Bakhtin e Voloshinov (1988, p. 34) a "lógica da consciência é a lógica da comunicação ideológica, da interação semiótica de um grupo social". A consciência individual depende dos signos para existir, e está presa à mesma lógica que regula o funcionamento dos signos. Nessa linha, o estudo das ideologias não deve estar relacionado à psicologia, pois a realidade dos fenômenos ideológicos é antes ainda a realidade dos signos sociais. "A realidade ideológica é uma superestrutura situada imediatamente acima da base econômica. A consciência individual não é o arquiteto dessa superestrutura ideológica, mas apenas um inquilino do edifício social dos signos ideológicos." (BAKHTIN; VOLOSHINOV, 1988, p. 34).

Os responsáveis pela publicidade e comunicação do governo Temer não precisam necessariamente ter conhecimento das origens filosóficas da expressão para, ao retomála no slogan do governo Temer, materializar as ideologias contidas no lema. 0 enunciado é um acontecimento histórico que recupera um conjunto de enunciados anteriores, que, como foi exposto neste artigo, são constantemente reiterados em diversos discursos como o empresarial eo da grande mídia.

A ideologia das classes dominantes de que o proletariado deve ser mantido afastado do poder em benefício do progresso, e de que o operariado é o responsável pela desordem, materializada pelo lema Ordem e Progresso, permanece sendo reiterada constantemente. Isso nos leva a refletir sobre os discursos fundantes da nação brasileira que continuam ecoando nos discursos da mídia tradicional, em que há uma reiteração dos limites da democracia brasileira para a participação política das classes baixas.

A retomada desse lema para compor um slogan de um governo que chega ao poder - por meio de uma manobra política - seria, possivelmente, uma tentativa de dar, de algum modo, legitimidade para o golpe impetrado contra a presidente Rousseff e o 
Partido dos Trabalhadores.

Segundo esse discurso, o seu afastamento do cargo teria sido um ato necessário para o progresso do país. Temer, como um representante das elites que sempre governaram o país, viria para restabelecer a ordem com vistas ao progresso, o qual o proletariado não seria - no discurso das classes dominantes, de Augusto Comte e dos positivistas que elaboraram a bandeira brasileira - capaz de levar adiante. $O$ discurso de Comte faz parte de uma construção de pensamento que transcende seu pensamento; ele dá um verniz filosófico à ideologia dominante.

O lema criado pela elite do século XIX parece retornar mais uma vez com a volta de um representante dessas elites ao poder.

\section{Referências}

BAKHTIN, Mikhail Mikhailovich. Estética da criação verbal. São Paulo: Martins Fontes, 1992.

BAKHTIN, Mikhail Mikhailovich; VOLOSHINOV, Valentin Nikoláievitch. Marxismo e filosofia da linguagem: problemas fundamentais do método sociológico na ciência da linguagem. São Paulo: Hucitec, 1988.

BENOIT, Lelita Oliveira. Augusto Comte: fundador da física social. São Paulo: Moderna, 2002.

BENVENISTE, Émile. Problemas de lingüística geral II. Campinas: Pontes, 1989.

BOCCHINI, Bruno. Fiesp volta a defender impeachment da presidenta Dilma. Agência Brasil, São Paulo, 17 mar. 2016. Disponível em https://agenciabrasil.ebc.com.br/politica/noticia/2016-03/fiesp-volta-defenderimpeachment-da-presidenta-dilma. Acesso em: 13 abr. 2020.

CÂMARA DOS DEPUTADOS. PL 2179/2003. Altera a Lei no 5.700, de $1^{\circ}$ de setembro de 1971, que dispõe sobre a forma e a apresentação dos Símbolos Nacionais. Substitui a expressão "Ordem e Progresso" da Bandeira Nacional pela expressão "Amor, Ordem e Progresso". Brasília: Câmara dos Deputados, 8 out. 2003. Disponível em: https://www.camara.leg.br/proposicoesWeb/fichadetramitacao?idProposicao=136692. Acesso em: 15 abr. 2020.

COMTE, Auguste. Catéchisme positiviste, ou sommaire exposition de la religion universelle en treize entretiens systématiques entre une femme et un prêtre de I'humanité. Paris: Apostolat positiviste, 1848.

COMTE, Auguste. Cours de philosophie positive: tome I. Paris: Rouen Frères (Bachelier), 1830. 
COMTE, Auguste. Système de politique positive, ou traite de sociologie, instituant la religion de l'humanite: tome premier: discours preliminaire, et introduction fondamentale. Paris: Librairie Scientifique-Industrielle de L. Mathias, 1851.

COMTE, Auguste. Système de politique positive, ou traite de sociologie, instituant la religion de l'humanité: tome deuxieme: statiques sociale ou le traite abstrait de l'ordre humain. Paris: Librairie Scientifique-Industrielle de L. Mathias, 1852.

COMTE, Auguste. Système de politique positive, ou traite de sociologie, instituant la religion de l'humanite: tome quatrieme et dernier : tableau synthetique de l'avenir humain. Paris: Librairie Scientifique-Industrielle de L. Mathias, 1854.

DUCROT, Oswald. O dizer e o dito. Campinas: Pontes, 1987.

ELITES empresariais paulistas: depoimentos à FGV. Rio de Janeiro: FGV, 2011.

FIESP esclarece noticiário sobre operação da polícia federal. Portal Fiesp, São Paulo, 26 mar. 2009. Disponível em: https://www.fiesp.com.br/noticias/fiesp-esclarece-noticiariosobre-operacao-da-policia-federal/. Acesso em: 14 abr. 2020.

GOMES, Laurentino. 1889: como um imperador cansado, um marechal vaidoso e um professor injustiçado contribuíram para o fim da Monarquia e a Proclamação da República no Brasil. São Paulo: Globo, 2013.

GOUHIER, Henri. La vie d'Auguste Comte. 2. ed. Paris: Librairie philosophique J. Vrin, 1965.

GOVERNO Federal: ordem e progresso" será o slogan de temer. Política e poder. Jornal De Brasília, Brasília, 12 maio 2016. Disponível em: jornaldebrasilia.com.br/politica-epoder/governo-federal-ordem-e-progresso-sera-o-slogan-de-temer. Acesso em: 15 abr. 2020.

GRANGE, Juliette. Le vocabulaire de Comte. Paris: Edité par Ellipses, 2002.

LACERDA, Gustavo Biscaia. Elementos estáticos da teoria política de Augusto Comte: as pátrias e o poder temporal. Revista de Sociologia e Política, Curitiba, n. 23, p. 63-78, 2004.

LAGARRIGUE, Juan Enrique. Segunda carta á la señora Doña Emilia Ralrdo Bazán. Santiago de Chile: Imprenta Cervantes, 1889.

MAINARDI, Diogo. Lula é minha anta. Rio de Janeiro: Record, 2007.

MARX, Karl; ENGELS, Friedrich. A ideologia alemã: crítica da mais recente filosofia alemã em seus representantes Feuerbach, B. Bauer e Stirner, e do socialismo alemão em seus diferentes profetas. São Paulo: Boitempo, 2007.

MENDES, Raymundo Teixeira. A bandeira nacional. 3. ed. Rio de Janeiro: Igreja Pozitivista do Brazil, 1958. 
MOURA BRASIL, Felipe. Veja o panorama do desgoverno Dilma no fim de 2015. Site da revista Veja, São Paulo, 9 fev. 2017. Disponível em:

https://veja.abril.com.br/blog/felipe-moura-brasil/veja-o-panorama-do-desgovernodilma-no-fim-de-2015. Acesso em: 13 abr. 2020.

O DESGOVERNO de Dilma produziu distorções em relação ao orçamento. Rádio Jovem Pan, São Paulo, 29 out. 2015. Disponível em: https://jovempan.com.br/opiniao-jovempan/o-desgoverno-de-dilma-produziu-distorcoes-em-relacao-ao-orcamento.html. Acessao em: 13 abr. 2020.

PECHEUX, Michel. Semântica e discurso: uma crítica à afirmação do óbvio. Campinas: Editora da Unicamp, 1997.

VENCESLAU, Paulo; ROCHA, André Ítalo. Fiesp anuncia apoio ao impeachment de Dilma. O Estado de São Paulo, São Paulo, 14 dez. 2015. Disponível em: https://politica.estadao.com.br/noticias/geral,fiesp-declara-apoio-formal-aoimpeachment-de-dilma,10000004821. Acesso em: 14 abr. 2020. 